\title{
Katharina Krisor-Wietfeld
}

\section{Rahmenbedingungen der Grundrechtsausübung}

Insbesondere zu öffentlichen Foren als Rahmenbedingung der

Versammlungsfreiheit

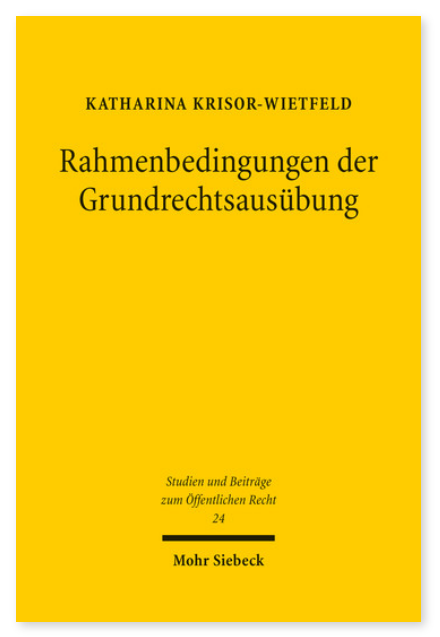

Aus Anlass der sogenannten Fraport-Entscheidung des BVerfG vom 22.02.2011 (BVerfGE 128, 226) widmet sich Katharina Krisor-Wietfeld (Rahmen-)Bedingungen, die zur Ausübung grundrechtlicher Freiheit erforderlich sind. Am Beispiel öffentlicher Foren ordnet sie Rahmenbedingungen der Versammlungsfreiheit - die in der Regel nicht der Verfügungsbefugnis der Grundrechtsträger unterliegen - in die Grundrechtsdogmatik ein, wobei sie die insoweit einschlägige Rechtsprechung aus den USA und Kanada rechtsvergleichend hinzuzieht.

Das Werk gibt auch eine Antwort auf die Frage, ob mit der Entstehung von Freiheitsvoraussetzungen in einem von privaten Rechtssubjekten beherrschten Bereich Freiheitsverluste einhergehen oder die Grundrechte ihre tatsächlichen Voraussetzungen sowohl gegenüber Einschränkungen aus der staatlichen als auch aus der privaten Sphäre schützen. Die Arbeit schließt mit einem konkreten Gesetzgebungsvorschlag ab.

Katharina Krisor-Wietfeld Geboren 1985; Studium der Rechtswissenschaft in Bochum und Tours (Frankreich); Erwerb der Licence en droit; seit 2010 wissenschaftliche Mitarbeiterin am Lehrstuhl für Öffentliches Recht und Europarecht der RuhrUniversität Bochum; 2012 Forschungsaufenthalt an der Duke University Law School in Durham North Carolina (USA); seit März 2014 Rechtsreferendariat am Landgericht Bochum; 2015 Promotion.

2016. XXV, 303 Seiten. StudÖR 24

ISBN 978-3-16-155688-3

DOI 10.1628/978-3-16-155688-3

eBook PDF $94,00 €$

ISBN 978-3-16-153864-3

fadengeheftete Broschur 94,00€

Jetzt bestellen:

https://mohrsiebeck.com/buch/rahmenbedingungen-der-grundrechtsausuebung-9783161556883?no_cache=1

order@mohrsiebeck.com

Telefon: +49 (0)7071-923-17

Telefax: +49(0)7071-51104 